\title{
Adolescent Users of Chewable Tobacco: Male / Female Personality Comparisons
}

\author{
Dr. Priya Rajkumar ${ }^{1 *}$, Dr. Dipti Christian ${ }^{2}$
}

\section{ABSTRACT}

Prevalence of chewable tobacco among adolescents has multiplied incite of ban on tobacco products. The study compares personality characteristics of 275 male and female users of chewable tobacco (gutkha, kharra) between 12 to 18 years using catell's high school personality questionnaire.

Significant differences were seen in intelligence levels with female users scoring less on intelligence (3.35) than male users (3.81). F females scored higher in expediency and evasion of rules (9.34) than males (10.38) and also had lower levels of self discipline and control (9.72) as compared to males (10.50).

Programs for tobacco cessation need to build trust and rapport at initiation stage, target female users keeping in mind their more assertive self image and incorporate meaningful unstructured activities for them.

Keywords: Chewable tobacco, Adolescent Users, Personality

Tobacco is the only legal drug that kills many of its users. WHO estimates that tobacco use (smoking and smokeless) is currently responsible for the death of about six million people across the world each year'The majority of tobacco-related deaths are expected to occur in developing countries, where tobacco use is on the rise. ${ }^{\text {ii }}$

In India tobacco is consumed in smoked and non smoked forms. Smoked forms include beedis, cigarettes, pipe, cigar, hukka, chutta of which beedi is most common since it is affordable. Among the non smoked forms - chewable tobacco is consumed in the form of tobacco lime mixture, kharra, khaini, gutkha, pan masala, kimam and in the inhaled form as tobacco snuff. iii

\footnotetext{
${ }^{1}$ PHD. Research Scholar, Department of Psychology, Hislop College, Rashtrasant Tukdoji Maharaj Nagpur University (RTMNU), Maharashtra, India

${ }^{2}$ Principal Hislop College, Head of Department of Psychology, Hislop College, Rashtrasant Tukdoji

MaharajNagpur University (RTMNU), Maharashtra, India

*Responding Author

(C) 2016 I P Rajkumar, D Christian; licensee IJIP. This is an Open Access Research distributed under the terms of the Creative Commons Attribution License (http://creativecommons.org/licenses/by/2.0), which permits unrestricted use, distribution, and reproduction in any Medium, provided the original work is properly cited.
} 
Betel quid (a combination of betel leaf, areca nut and slaked lime with preferred flavorings) and gutka (crushed areca nut, tobacco, catechu, paraffin wax, slaked lime and flavorings) use is reported to have stimulant and relaxation effects. Pan masala is basically a preparation of areca nut, catechu, cardamon, lime and a number of natural and artificial perfuming and flavoring materials.

With the emergence of commercial pan masala and gutkha about three decades ago, the Indian market witnessed massive growth not only in the sales of smokeless tobacco and areca nut products, but also a huge worldwide export market. The packaging revolution has made these products portable, cheap and convenient, with the added advantage of a long shelf-life. Many states of India have banned the sale, manufacture, distribution and storage of gutka and all its variants. However, enforcement of the law is generally lax and many shops still sell gutka, although it may not be openly displayed.

Conditions and Cancers associated with using betel quid/ gutka include precancerous conditions (oral precancerous lesions-erythoplakia, leukoplakia, oral sub mucous fibrosis), oral cancers, poor reproductive health outcomes and cardiovascular disease. ${ }^{\text {iv }}$

Oral cancer is the sixth most common in the world and areas of high incidence are in South East Asia and particularly India which has a higher population incidence rate of oral squamous cell carcinoma (OSCC). The prognosis for oral cancer in India is poor due to lesser early detection and poorly trained clinicians.

\section{Increasing Trend of chewable tobacco use among school children and youth}

The prevalence of tobacco use among Indian youth (10,112 school going students aged 13 to 15 years) indicated that $14.6 \%$ students currently use tobacco $-4.4 \%$ smoke and $12.5 \%$ use other forms or tobacco. ${ }^{\mathrm{v}}$

Chewable tobacco products are typically consumed throughout the day. A number of small surveys conducted in schools and colleges in several states of India have shown that 13-50\%of students chew pan masala and gutkha on a regular basis (Guptaand Ray, 2003). Influences to use tobacco included parental use, peer pressure, advertisements and colorful packaging. ${ }^{\mathrm{vi}}$

A random survey ${ }^{\mathrm{vii}}$ among rural school children in five villages around Mullanpur, Punjab State, covering 100 students from 5 schools, was conducted with the objective of finding out the extent of gutkha use. 66 of the students regularly used gutkha, 19 consumed it every day and most of them were from the 7th or 8th standard. The widespread availability of gutkha at roadside stands, tea stalls, cigarette shops and grocery stores and even bookshops makes access easy and convenient. Another study was conducted in rural southern TamilNadu, rural Gujarat, and slum semiurban areas in Bangalore, Karnataka which found that nearly 50\% of rural children, boys more than girls, experiment with tobacco, mostly as snuff (nashyna, chhinkni) even by 10 years 
of age. Snuff use decreases, while smoking and chewing increase with age. Smoking is better known as a health hazard than chewing or use of snuff.

The Goa Cancer Society conducted several epidemiological studies viii to determine the prevalence of tobacco habits among school-children and adults. They found that about $13.4 \%$ of boys and $9.5 \%$ of girls used tobacco, mostly of the smokeless variety. They began use as early as five years of age and most were introduced to tobacco use by family members and friends.

A number of surveys conducted in households in India have shown that pan masala and gutka are commonly chewed by children and adolescents, especially in Gujarat, Maharashtra and Bihar. In a survey of 1200 students from junior and degree colleges of Maharashtra, 9.9\% chewed pan masala and 9.6\% chewed gutka. In a survey of 95 boys and girls in the 8th and 9th grades (13-14 years old) of a small-town private school in Anand, Gujarat, $16 \%$ used gutka. In a village community of Kheda District, Gujarat, $72 \%$ of men and 50\% of women under 26 years of age used tobacco products. Men favoured bidis and gutka while women preferred gutka and tobacco toothpaste. Among high school students in classes 10-12 (15-17 years old) in Patna, Bihar, approximately $12 \%$ used pan masala (Gupta \& Ray, 2002).

\section{Factors associated with Tobacco Chewing}

In the GATS Survey in India, the prevalence of smokeless tobacco use was nearly twice as high in rural areas compared to urban ones; it was higher in those without formal education (twice as high in men, eight times higher in women). The poorest people who are the most nutritionally disadvantaged and can least defend themselves from harmful chemicals in smokeless tobacco; are more at risk for tobacco related cancers.

Some of the psychosocial factors leading to initiation of tobacco use include family history of tobacco use by elders, peer influence, experimentation, easy access to tobacco products, personality factors, underlying emotional and psychological problems and accompanied risk taking behaviours.

Poor school performance, truancy, low aspiration for future success and dropping out of school has also been found to be associated with tobacco initiation. Children and adolescents with anxiety and depression are also more likely to use tobacco and other drugs, as these products have anxiety relieving and mood elevating properties.

\section{METHODOLOGY}

Purposive sampling was done in which 140 male and 135 female tobacco users in the age group of 12 to 18 years were selected as the sample. Some were studying in government and semiprivate schools and others were working in construction sites as labourers. Contacts with nonschool going adolescents were made through peers and among those living in low income group residential areas. Through a method known as 'snowballing' identified users of chewable 
tobacco products helped to identify other users. In some cases, the help of roadside vendors of tobacco products were taken to identify regular users.

For the purpose of the study adolescents who were regular tobacco users were selected based on the following criteria

a. Currently chews at least two packets of kharra in a day And/ or

b. Currently chews at least two to four packets of gutka in a day.

A Non tobacco user were those adolescents who had never consumed tobacco products

R. B. Cattell and Cattell. High School Personality Questionnaire (Cattell et al., 1984) which measures primary personality dimensions It contains 142 items in each form and is meant for age 12-18 years. The time required for completion of the tool is 40 minutes.

\section{Statistical Analysis}

The independent variable was that of sex which was varied at 2 levels namely male and female. The dependent variables were the 14 different personality characteristics (i) reserved versus outgoing, (ii) less intelligent versus more intelligent, (iii) affected by feelings versus emotional stability (iv) phlegmatic versus excitable, (v) obedient versus assertive, (vi) sober versus happy go lucky, (vii) expedient versus conscientious (viii) shy versus venturesome, (ix) tough minded versus tender minded (x) vigorous versus doubting (xi) placed versus apprehensive (xii) group dependent versus self sufficient (xiii) undisciplined self conflict versus controlled and (xiv) relaxed versus tense.

Mean and standard deviation was calculated and test was used to find out the significance of mean differences among males and females for the 14 personality dimensions.

\section{Hypothesis}

Personality dimensions of male adolescent tobacco users vary significantly from female adolescent tobacco users in at least 7 out of 14 personality factors.

\section{RESULTS AND DISCUSSION}

In the present study the factor of sex served as the independent variable and the 14 personality dimensions of the High School Personality Questionnaire (Cattell 1984) were treated as the dependent variables. The sample of 275 adolescents (between 12 to 18 years) were all regular users of chewable tobacco on a daily basis ie. Kharra/ gutkha or both. Means and SDs were obtained for both the groups i.e. male and female tobacco users. As a next step, the $t$ values for each of the personality factors were calculated to find out if they were significant.

The means and standard deviations of each personality factor as well as the accompanying $t$ values are presented in the table below. 
Adolescent Users of Chewable Tobacco: Male / Female Personality Comparisons

Means and standard deviations Male and Female Tobacco chewers for 14 Personality Factors

\begin{tabular}{|c|c|c|c|c|c|}
\hline Factor & & Males & Female & (t) & \\
\hline \multirow{2}{*}{$\begin{array}{l}A \quad-\quad \text { Reserved vs } \\
\text { Outgoing }\end{array}$} & $X$ & 8.77 & 9.16 & 1.11 & \multirow[t]{2}{*}{ Non-significant } \\
\hline & $S$ & 2.81 & 3.04 & & \\
\hline \multirow{2}{*}{$\begin{array}{l}\text { B - Less Intelligent vs } \\
\text { More Intelligent }\end{array}$} & $X$ & 3.81 & 3.35 & & \multirow{2}{*}{$\begin{array}{l}(t=2.52, \quad d f=273, \\
p>0.05)\end{array}$} \\
\hline & $S$ & 1.57 & 1.49 & 2.52 & \\
\hline \multirow{2}{*}{$\begin{array}{l}C \text { - Affected by feelings } \\
\text { vs Emotionally Stable }\end{array}$} & $X$ & 10.52 & 10.83 & 0.87 & \multirow[t]{2}{*}{ Non-significant } \\
\hline & $S$ & 3.15 & 2.68 & & \\
\hline \multirow{2}{*}{$\begin{array}{l}\text { D- Phlegmatic vs } \\
\text { Excitable }\end{array}$} & $X$ & 9.76 & 9.67 & 0.20 & \multirow[t]{2}{*}{ Non-significant } \\
\hline & $S$ & 3.23 & 3.77 & & \\
\hline \multirow{2}{*}{$\begin{array}{l}E \quad \text {-Obedient vs } \\
\text { Assertive }\end{array}$} & $X$ & 9.34 & 9.62 & 0.71 & \multirow[t]{2}{*}{ Non-significant } \\
\hline & $S$ & 3.44 & 3.11 & & \\
\hline \multirow{2}{*}{$\begin{array}{l}\text { F - Sober vs Happy Go } \\
\text { Lucky }\end{array}$} & $X$ & 10.50 & 10 & 1.35 & \multirow[t]{2}{*}{ Non-significant } \\
\hline & $s$ & 2.91 & 3.21 & & \\
\hline \multirow{2}{*}{$\begin{array}{l}G \quad-\text { Expedient vs } \\
\text { Conscientious }\end{array}$} & $X$ & 10.38 & 9.34 & 2.46 & \multirow{2}{*}{$\begin{array}{l}(t-2.46, \quad d f=273, \\
p>0.05)\end{array}$} \\
\hline & $s$ & 3.37 & 3.63 & & \\
\hline \multirow{2}{*}{$\begin{array}{l}H \quad \text { - Shy versus } \\
\text { Venturesome }\end{array}$} & $X$ & 9.91 & 9.65 & 0.68 & \multirow[t]{2}{*}{ Non-significant } \\
\hline & $S$ & 3.01 & 3.21 & & \\
\hline \multirow{2}{*}{$\begin{array}{l}\text { I - Toughminded versus } \\
\text { Tenderminded }\end{array}$} & $X$ & 10.59 & 10.85 & 0.62 & \multirow[t]{2}{*}{ Non-significant } \\
\hline & $s$ & 3.22 & 3.74 & & \\
\hline \multirow{2}{*}{$\begin{array}{l}J \text { - Vigorous versus } \\
\text { Doubting }\end{array}$} & $X$ & 9.30 & 9.65 & 1.07 & \multirow[t]{2}{*}{ Non-significant } \\
\hline & $S$ & 3.01 & 2.41 & & \\
\hline \multirow{2}{*}{$\begin{array}{l}\text { O } \quad \text {-Placid versus } \\
\text { Apprehensive }\end{array}$} & $X$ & 10.27 & 10.23 & 0.11 & \multirow[t]{2}{*}{ Non-significant } \\
\hline & $S$ & 3.00 & 3.19 & & \\
\hline \multirow{2}{*}{$\begin{array}{l}\text { Q2 -Group Dependent } \\
\text { versus Self sufficient }\end{array}$} & $X$ & 10.32 & 9.74 & 1.53 & \multirow[t]{2}{*}{ Non-significant } \\
\hline & $s$ & 3.09 & 3.22 & & \\
\hline \multirow{2}{*}{$\begin{array}{l}\text { Q3 } \text {-Undisciplined Self } \\
\text { conflict versus } \\
\text { Controlled }\end{array}$} & $X$ & 10.50 & 9.72 & 1.96 & \multirow{2}{*}{$\begin{array}{l}(t=1.96, \quad d f=273, \\
p=0.05)\end{array}$} \\
\hline & $S$ & 3.10 & 3.51 & & \\
\hline \multirow{2}{*}{$\begin{array}{l}\text { Q4 - Relaxed versus } \\
\text { Tense }\end{array}$} & $X$ & 9.06 & 9.19 & 0.37 & \multirow[t]{2}{*}{ Non-significant } \\
\hline & $S$ & 3.19 & 2.95 & & \\
\hline
\end{tabular}

(t value at 0.05 is 1.96 and for 0.01 is 2.57 )

On the reserved versus outgoing dimension (Factor A), male and females tobacco users have a mean of 8.77 (male) and 9.16 (female) and the resulting sten score of 4 indicates that there is an inclination towards the reserved dimension. This personality factor indicates that users may be critical, cool, aloof, precise and objective, distrustful and rigid, standing by their own ideas rather than cooperating with others. There is no significant difference between the means of male and female users. 
On Factor B which relates to intelligence the mean scores of male and females is the lowest of all the dimensions. (Male - 3.81 and female 3.35). Intelligence has an association with personality in that it influences relationship with peers, adjustment in school and indicates general ability of the adolescent. In this case, Male tobacco users have a significantly higher level of intelligence as compared to females. $(\mathrm{t}=2.52, \mathrm{df}=273, \mathrm{p}>0.05)$. Though this brief scale is not sufficient to accurately measure the level of intelligence comprehensively, it is indicative of academic interest and general mental capacity. Females who participated in this study were mostly dropouts and discontinued school after primary or middle school to work at home or in the construction sites. Reading and writing were unfamiliar to many of them and they had to be administered the questionnaire verbally. Poor functional literacy and comprehension skills among female users were clearly evident. The overall level of mental capacity of users is low.

Factor C relates to Emotional instability versus stability. Both male and female users have near similar means (male 10.52 and female 10.83) with a sten score of 6, indicating that they are in the average range with regards to this personality dimension. There is a marginal tendency towards the positive expression of this personality dimension, particularly among the females - to be more emotionally mature, calm, stable and unruffled. Lower scores on this dimension are indicative of neurotic tendencies. Users do not show tendency towards emotional instability, worry or get frustrated when upset. Their attitudes and interests are not easily changed. It is therefore fair to surmise that users will be more willing participants in youth friendly tobacco cessation programs.

Phlegmatic temperament versus Excitable temperament is described as Factor D. Males and females have means in the range of 9.76 (male) and 9.67 (female) with a sten score of 5 indicating average level of this dimension leaning towards phlegmatic, inactive, constant behavior. There is no significant difference in the mean scores of males and female users through males have a slight tendency to be more excitable, impatient and demanding as compared to females. Higher scores of this dimension relate to juvenile delinquency.

Factor E describes the obedient versus assertive personality dimension. Female users (9.62) have a tendency to be more assertive and independent as compared to male users (9.34). There is no significant difference in the means of male and female users. However the sten score of 6 indicates an average level of this dimension leaning towards assertiveness rather than obedience and submission.

Sober versus Happy go lucky dimension is Factor F. On this dimension Males and females scored 10.50 and 10 respectively. The sten score is 6 . Users are therefore on an average level as far as this personality characteristic is concerned. Users do not show signs of desurgency (sober, serious, silent, incommunicative) and have a tendency to be happy go lucky, talkative, cheerful and enthusiastic indicating that they may be popular with peers and are well adjusted at school. There are no significant differences between male and female scores. 
Factor $\mathrm{G}$ is the Expedient versus conscientious personality dimension. On this dimension, Males have a mean of 10.38 and females, 9.34. The related sten scores are 5 for males and 4 for females. There is also a significant difference in the means of females and males $(t=2.46, \mathrm{df}=273$ and $\mathrm{p}>0.05$ ). The scores indicate that both males and females have signs of expediency in their personalities, particularly girls. Expedient behavior is best described as a lack of acceptance of group moral standards, disregards for rules, low superego strength, frivolous and self indulgent. It is interesting to note that females have scores indicating higher levels of higher expediency than males. Exposure to media glorifying dominant traits in females, pressure to imitate male independence as well as enjoy greater social freedom may influence female users to evade rules and feel fewer 'traditional' social obligations. Lower scores on Factor $\mathrm{G}$ are also associated with delinquency and defiance of law and order.

The shy versus venturesome personality dimension is designated as Factor H. Males and female users scored 9.91 and 9.65 respectively with a sten score of 5. There is no significant difference between male and female user scores. However, users may have a tendency to be shy, restrained and timid as opposed to being venture some, socially bold and uninhibited.

Factor $\mathrm{I}$ is the tough minded versus tender minded personality dimension. There are no significant gender differences in the mean scores obtained by male(10.59) and female (10.85) users on this dimension. The related sten score of 5 indicates the tendency to be tough minded, self reliant and realistic.

The next dimension (Factor J) relates to Vigorous versus doubting. Male and female users have scores of 9.30 and 9.65 with no significant differences between them. The related sten score of 6 indicates that users can act individualistically, be guarded, internally restrained and unwilling to act. It seems that users may have fewer friends, may avoid arguments and keep in the background.

Factor $\mathrm{O}$ relates to placid versus apprehensive dimension. On this dimension, male and female users have a sten score of 6 and a mean of 10.27 for males and 10.23 for females. There is no significant difference between the sexes on this dimension. The sten score of 6 indicates a leaning towards the apprehensive dimension, characterized by worrying, depressive, troubled behavioural tendencies. However it is in the average range and may not be a dominant personality characteristic.

The Factor Q2, dimension of group dependent versus self sufficient has scores of 10.32 for males and 9.74 for females. There is no significant difference between males and females and the sten score of 6 is average. It shows that users may be more self sufficient, prefer to make their own decisions and are more resourceful. They are not group dependent and are not 'followers'. During the course of data collection, it was observed that male users in schools have their own 
groups which usually consist of other users. They also share their daily quota of kharra or gutka with each other. This group also maintains a social distance from those who are non users.

Factor Q3, is described as undisciplined self-conflict versus controlled. In this factor, males have scored 10.50 and females 9.72 and there is a significant difference between them $(t=1.96$, $\mathrm{df}=273, \mathrm{p}=0.05$ ). The sten score for this dimension for both males and females is 5 and there is a tendency towards undisciplined self conflict, though average. Users may therefore have a tendency to follow their own urges and be careless of protocol rather than being self disciplined and socially precise. This indicates that tobacco cessation programs should be more informal and less structured to appeal to the users. Scores leaning towards undisciplined self conflict indicate juvenile delinquency and scores leaning towards the opposite dimension are predictive of occupational and scholastic success.

The last Factor Q4, is relaxed versus tense and this dimension has scores of 9.06 for males and 9.19 for females. There is no significant difference between the sexes and the sten of 5 shows a leaning towards the relaxed side of this personality dimension. Both male and female users show a tendency to be tranquil, torpid and frustrated. Regular use of chewable tobacco also produces relaxing effects which may lead to a state of diminished alertness.

\section{DISCUSSION}

The present study focused on the personality characteristics of male and female chewable tobacco users to assess dominant personality characteristics as well as probe for sex differences in the personality makeup of male and female users. In all 275 adolescents in the 12 to 18 year age group (140 male and 135 female) were administered Catell's High School Personality Questionnaire (HSPQ). All were regular users of gutkha/ kharra, now banned by the Maharashtra Government but sold illegally.

Review of the results of the statistical interpretation leads us to the conclusion that there is no major distinguishing personality characteristic among the users, both male and female. Most of the personality measures are in the medium or average range save for three factors which have extreme low level sten scores (between 2 to 4 on a scale of 10). This includes the level of intelligence (Factor B), reserved versus outgoing (Factor A), Expedient versus Conscientious (Factor $\mathrm{G}$ ) which have extreme scores (sten score between 2 to 4 ).

The intelligence scale was included in the HSPQ to complement the assessment of other personality measures taking into account that intelligence strongly influences the personality of the adolescent. In this study both males and females have low intelligence levels (sten score of 2) with females having lower intelligence levels as compared to males. Though the intelligence scale is by no means a comprehensive assessment of intelligence it is an estimate which it worth noting. The possible reasons for low intelligence scores may be the adolescents' not being 
familiar with questionnaires and questions related to intelligence, poor quality of education, low reading and writing skills and being a dropout.

The measure related to Reserved versus outgoing (Factor A), shows that the users (both males and females) are mostly reserved by nature. Their tendency towards detachment, critical outlook and distrustful attitude keep them away from the larger group and they do not readily participate in group activities. Programs for tobacco cessation may need to build spend adequate time to build rapport, involvement, trust and build relationships with adolescent users at the preliminary stages.

Male and female users show a significant difference in the personality measure of Expediency versus conscientious. While expediency figures prominently in personality profiles of other drug users such as heroin and marijuana, it is interesting to note that females have higher scores than males in expediency, in this study. The breakdown of traditional female stereotypes which promotes assertiveness, equality with men and boldness rather than feminine submissiveness may have influenced higher levels of expediency among girls. To strengthen this finding, females have higher scores than males in Factor E which is Obedient versus Assertive. They show more assertiveness and independence as compared to male users. Tobacco cessation programs for female users need to keep in mind that they prefer roles which allow for assertiveness and independence rather than submissiveness and may respond more positively to strong willed and bold female role models.

The fourth and last factor which shows significant difference between male and female users in the Undisciplined self-conflict versus controlled dimension (Factor Q3). The males show higher levels of control and self discipline while the females lean towards undisciplined self conflict, following their own urges and careless of protocol. It does seem that females show more signs of delinquency in this particular factor as compared to males. The female users in this study were school dropouts and many of them worked as daily labourers in construction sites. Social factors may have influenced the scores of the female users. They live in a culture with fewer do's and don'ts and lesser social restrictions.

The hypothesis framed for the study -Personality dimensions of male adolescent tobacco users vary significantly from female adolescent tobacco users in at least 7 out of 14 personality factors, is not fulfilled. There were only 3 significant personality differences among male and female tobacco users namely intelligence, (females had lower levels of intelligence than males), expediency versus conscientiousness (females had higher levels of expediency) and undisciplined self conflict and controlled (females scored more towards undisciplined self conflict)

It is interesting to note that there are more similarities and lesser differences among male and female users which means that similar programs can be designed for them. Both male and female 
users do not show dominant characteristics and are average in most of the personality dimensions. i.e. Factor C - Affected by feelings versus, Emotionally stable, Factor D Phlegmatic versus Excitable, Factor E - Obedient versus Assertive, Factor F - sober versus happy go lucky, Factor $\mathrm{H}$ - Shy versus venturesome, Factor I - tough minded versus tender minded, Factor J - Vigorous versus doubting, Factor O - Placid versus apprehensive, Factor Q2 - Group dependent versus self sufficient and Factor Q4 - Relaxed versus tense.

In the India Global School Personnel Survey 2006, nearly one in five (16.3\%) school personnel reported to have ever received training to prevent youth from tobacco use. Alarmingly over one third of school personnel used chewable tobacco themselves. $66 \%$ of the current student tobacco users wanted to stop but there are few if any effective tobacco cessation programs at the school level. There is increasing interest in developing treatment approaches that match adolescent personality profiles.

Personality can therefore be a protective or risk factor and influences how adolescents deal with stressful situations, playing a role in self regulation and influencing inadequate coping strategies such as addiction, violence and delinquency.

Personality traits are associated with the outcome of therapeutic interventions. Although individual treatments might reduce the rate of drug abuse, public policy is an important tool for cigarette smoking and other drug abuse prevention and cessation. Because of the low conscientiousness, high impulsivity, and high emotional vulnerability of most drug users, relying on an individual's resources, without therapeutic intervention, may produce limited results.

The personality trait effects were found to influence treatment plans and tailor therapeutic interventions to individual needs. However more research is needed to find out how personality traits and their measure can be used effectively to inform the choice of treatment plans for substance users.

\section{REFERENCES:}

${ }^{\mathrm{i}}$ WHO global report on trends in prevalence of tobacco smoking 2015

ii The World Bank 1999; Warren et al. 2008

iii Textbook of Oral and Maxillofacial surgery - Rajiv M Borle, J P Medical Ltd, 28 Feb 2014

${ }^{\text {iv }}$ WHO International Agency for Research on Cancer (IARC) Monographs on the Evaluation of Carcinogenic Risks to Humans Volume 85 Betel Quid and areca nut chewing and some areca nut derived nitrosamines Global Youth Tobacco Survey, India 209 - WHO and US Centre for Disease Control

v Global Youth Tobacco Survey India, 2009 
${ }^{v i}$ Gupta, P.C., Ray, C.S., Sinha D. N., Singh P.K., (2011). Smokeless tobacco: A major public health problem in the South East Asia Region: A review , Indian Journal of Public Health, Year 2011, volume 55, Issue 3, Pg 199-209

vii Patel S., Shah R., Pati H., Gandhi P., Bhatt S., Venkur G.K.,(1998) Awareness and use of substances among high school students. Abstracts of scientific papers presented at the Golden Jubilee Annual National conference of the Indian Psychiatric Society, 1998. The Indian Journal of Psychiatry Vol. 40 Supplement, Tobacco used survey.

${ }^{\text {vii } V a i d y a ~ S . G ., ~ V a i d y a ~ N . S ., ~ N a l i k ~ U . D .,(1996) ~ V a i: ~ E p i d e m i o l o g y ~ o f ~ t o b a c c o ~ h a b i t s ~ i n ~ G o a, ~}$ India. In: Gupta PC Hamner JE, Murti PR eds: Control of tobacco related cancers and other diseases. International Symposium, 1990, Bombay, Oxford University Press 1992, cited in Traquet-Chollat C. Evaluating Tobacco Control Activities-Experiences and guiding principles, WHO, Geneva, 1996, pp 151-152.Tobacco used survey.

${ }^{v i i i}$ Chaddha R.K., Sengupta S.N., (2003) Tobacco Use by Indian Adolescents, Tobacco Induced Diseases, Published online 2002 Jun 15. doi: 10.1186/1617-9625-1-8, PMCID: PMC2669568

How to cite this article: P Rajkumar, D Christian (2016), Adolescent Users of Chewable Tobacco: Male / Female Personality Comparisons, International Journal of Indian Psychology, Volume 3, Issue 3, No. 5, DIP: 18.01.090/20160303 